\title{
Development and Evaluation of a Program to Improve Understanding of Physical and Mental Health of Older Primiparas and Strengthen Marital Relationships: A Semi-Experimental Study without Control Groups
}

\author{
Nakajima $K^{1 *}$, Hirose $A^{2}$ and Nameda $T^{3}$ \\ ${ }^{1}$ School of Nursing, Graduate School of Health Science, \\ Gunma Paz University, J apan \\ ${ }^{2}$ School of Nursing, Faculty of Health Science, Gunma Paz \\ University, J apan \\ ${ }^{3}$ School of Nursing, Graduate School of Nursing, Gunma \\ Prefectural College of Health Sciences, J apan \\ *Correspondling author: Nakajima K, School of \\ Nursing, Graduate School of Health Science, Gunma Paz \\ University, 1-7-1, Tonya-machi, Takasaki, Gunma, 370- \\ 0006, Japan
}

Received: J une 15, 2021; Accepted: July 06, 2021; Published: July 13, 2021

\begin{abstract}
Objectives: Older primiparas are more likely to be at risk for physical and mental health problems. The purpose of this study is to develop and evaluate a program to understand the physical and mental health of older primiparas and strengthen their marital relationship.
\end{abstract}

Design: A semi-experimental study of one group without control groups.

Method: Participants included 15 older primiparas Japanese couples who attended regular childbirth and childcare preparation classes held at two maternity hospitals in Japan. Participants responded to sociodemographic questions, Edinburgh Postnatal Depression Scale (EPDS), questions regarding understanding, satisfaction, and utilization of the program (process evaluation), and the Quality Marriage Index (QMI; outcome evaluation). Data was collected before the pregnancy program and one and three months after childbirth.

Results: Participants understood and were satisfied with the information provided in the program. There was no significant decrease in postpartum marital satisfaction after participating in the program. However, the usefulness assessment of the pregnancy program dropped to about $80 \%$ at one and three months after childbirth.

Conclusions: Findings indicate that this program improves mutual understanding and sharing of thoughts and feelings between couples. It was suggested that a postnatal program be held so that the couple could continue learning after childbirth.

Keywords: Older primipara; Marital relationship; Physical and mental health; Program development; Semi-experimental study design

\section{Abbreviations}

EPDS: Edinburgh Postnatal Depression Scale; QMI: Quality Marriage Index

\section{Introduction}

The maternal age in developed countries, including Japan, has been increasing. The proportion of older primiparas in the total number of births in Japan has increased from $11.9 \%$ in 2000 to $29.1 \%$ in 2019 [1]. There is concern that older primiparas over the age of 35 have a higher incidence of pregnancy and childbirth abnormalities. In addition, compared with young primiparas and multiparous women, older primiparas are more likely to be at risk for physical and mental health problems, leading to child-rearing anxiety and depression $[2,3]$.

For couples who become parents for the first time, adapting to the parent role in addition to their social role, is difficult. When a couple has children, the wife is overloaded with housework and childcare. If the husband does not understand the physical and mental burden faced by the wife, he would be unable to cooperate adequately. This can lead to decreased satisfaction with their marital relationship [4], and a postpartum crisis is likely to occur [5]. Our previous qualitative study of older, married primiparous couples revealed that husbands' support during pregnancy and one to three months after childbirth improved the physical and mental health of older primiparas leading to wives' satisfaction [6]. Furthermore, a continuous educational program encouraging smooth transition from pregnancy to parenthood is necessary for older primiparous couples. It is also important to provide information on how husbands can support their wives post childbirth, based on the mental and social strengths of older primiparous couples [7].

Anticipatory guidance is important because couples who become parents for the first time face a developmental crisis during pregnancy, childbirth, and postpartum [8]. In recent years, educational programs encouraging fathers to participate in childcare and housework have been developed [9]. Childbirth education classes that encourage small groups of couples to become parents have also developed [10]. These programs focus on teaching couple's childbirth and childcare
Ann Depress Anxiety - Volume 8 Issue 1 - 2021 ISSN : 2381-8883 | www.austinpublishinggroup.com Nakajima et al. (C) All rights are reserved
Citation: Nakajima K, Hirose A and Nameda T. Development and Evaluation of a Program to Improve Understanding of Physical and Mental Health of Older Primiparas and Strengthen Marital Relationships: A SemiExperimental Study without Control Groups. Ann Depress Anxiety. 2021; 8(1): 1105. 
skills and helping couples become parents. However, there are no programs that promote the development of intimacy between couples. Therefore, it is necessary to provide a program that works on the relationship between husband and wife during pregnancy to prevent postpartum crisis.

\section{Aim}

The purpose of this study is to develop a program to understand the physical and mental health of older primiparas and strengthen their marital relationship. Further, this study aims to evaluate the content of the program based on participant satisfaction, understanding and usefulness of information, and results based on the satisfaction of the marital relationships.

\section{Methods}

\section{Study design}

This study employs a semi-experimental design with before and after assessments of the program intervention for one group (older primiparas couples), without a control group.

\section{Participants}

Participants included older primiparas and their husbands who attended regular childbirth and childcare preparation classes held at two maternity hospitals in prefecture A. Participants were recruited using convenient sampling. The sample size was calculated using the power analysis software $G^{*}$ power3. As a result of calculating the intervention effect with a significance level of $\alpha=0.05$, an effect size of 0.80 , and a power of 0.80 , the sample size was 15 couples. Participants were required to satisfy the following inclusion criteria: (1) wives' age $\geq 35$ years, (2) couples who can participate in the study during pregnancy, and one and three months after childbirth, and (3) couples who can speak and understand Japanese. The following were the exclusion criteria: (1) pregnant wives and their infants with serious health problems and (2) couples with a mental illness. The program was implemented from April to August 2018.

\section{Program content and structure}

The framework of this program was built on the theory of adult education advocated by Knowles [11]. The program was developed by extracting the support needs for older primiparas couples and the contents to achieve the purpose and goals of the educational program. The purpose of this program was for couples to understand Table 1: Program contents.

\begin{tabular}{|c|c|}
\hline Time: Total 2 hours & The program contents \\
\hline Introduction (10 min) & - $\quad$ Self-introduction (Wife and Husband). \\
\hline - $\quad$ The lectures: Provided information (30 min) & $\begin{array}{l}\text { - The risks to physical and mental health of older primipara women. } \\
\text { - The differences in the couple's feelings. } \\
\text { - The key of good partnership and three points of husbands' supports. }\end{array}$ \\
\hline - The skit: Couple discussion (15 min) & $\begin{array}{l}\text { Two scenes of a postpartum couple relationship: } \\
\text { Case 1: Baby changing diaper } \\
\text { Case 2: Husband returning home. } \\
\text { Encourage couples to promote effective communication skills }\end{array}$ \\
\hline Break time (10 min) & Tea break \\
\hline $\begin{array}{l}\text { - The participatory exercises: Exchange of opinions } \\
\text { (25 min) }\end{array}$ & $\begin{array}{l}\text { - The couples described their feelings to each other and exchanged opinions with other } \\
\text { participants. } \\
\text { - Utilization of "couple's thought sheet" }\end{array}$ \\
\hline - The participatory exercises: Pair stretching (20 min) & $\begin{array}{l}\text { - Carried out pair stretching exercises: Prevention of low back pain, stiff shoulders, and } \\
\text { tendonitis }\end{array}$ \\
\hline Evaluation (10 min) & - $\quad$ Fill in the program evaluation questionnaire \\
\hline
\end{tabular}

the physical and mental risks for older primiparas, understand the key to a good partnership between couples, and share their thoughts and feelings with each other. The program had four goals: (1) ability of couple to understand the physical and mental risks for older primiparas during pregnancy, childbirth and postpartum, (2) to understand the difference, in the way of thinking, about the relationship between the wife and husband, (3) to understand the points for a good partnership and utilize them in postpartum marital relationships, and (4) to be able to share their thoughts and feelings after giving birth.

Participant needs were as follows: (1) to understand the physical and mental risks for pregnant and postpartum older primiparas $[12,6]$, and (2) to emphasize the importance of husbands' support for wives' satisfaction [6].

According to Knowles [11], adult education is expected to be effective in capturing learners' interests and solving real problems. Therefore, this program consisted of lectures, skits, and participatory exercises (Table 1). The education program was divided into four segments. First, the lecture used a booklet to provide information primiparas during pregnancy, childbirth, and postpartum, followed by a discussion surrounding three points about importance of husband's support for a good partnership. Second, the skit set up a postpartum childcare scene and encouraged couples to promote effective communication skills. Third, in participatory exercises, participants exchanged opinions about the role of communication between husband and wife and husband's support after childbirth, in increasing wives' satisfaction. After filling out the "Couple's Thinking Sheet", the participating couples discussed differences between husbands' support and wives' satisfaction. Finally, couples performed pair stretch exercises to reduce stiff shoulders, low back pain, and tendinitis caused by childcare after childbirth in older primiparas.

The program was held on weekends so couples could participate together. The program was held once during pregnancy for a duration of 2 hours.

The validity of the program content was revised by three maternal nursing and midwifery specialists and two older primiparas couples who reviewed the program content.

\section{Investigation procedure}

The principal investigator and co-researchers explained the to understand the physical and mental health risks for older 
purpose of the study to the older primiparous wives who participated in a maternity class at the hospital. The husbands were asked to cooperate in the research through their wives. The researchers distributed questionnaires and reply envelopes to each couple. The wife and husband put them in their respective envelopes and the questionnaire was collected as a couple set. The data collection period was from April 2018 to January 2019.

\section{Measurements}

- Attributes: Participants responded to sociodemographic questions regarding couple' age, working status, family living together, progress of pregnancy, and childcare situation (supporter/satogaeri; returning to their parents' home). Participants also completed the Edinburgh Postnatal Depression Scale (EPDS).

- $\quad$ Process evaluation: The process evaluation of the program consists of five items that indicate the satisfaction level of the program and three items that indicate the degree of understanding and utilization of the program. To confirm the sustainability of the program's effects, the degree of understanding and utilization of the program was conducted three times-after the pregnancy program and one and three months after childbirth. Participants responded on a 5-point Likert scale: agree, somewhat agree, neither agree nor disagree, somewhat disagree, and disagree. Higher scores indicated increased understanding and satisfaction. In addition, the opinions of the participants regarding the program were used as free description data.

- Outcome evaluation: The Quality Marriage Index (QMI) created by Norton (1983) [13] and translated into Japanese by Moroi [14] was used to measure outcome evaluation. Its reliability has been verified. The scale consists of six items that question the quality of marital relationships and is measured on a 4-point scale with scores ranging between 6-24 points. Higher scores indicated increased satisfaction with the marital relationship. In this study, to evaluate the wives' and husbands' satisfaction with marital relationships, measurements were taken before the pregnancy program and one and three months after childbirth.

\section{Analysis method}

- Quantitative analysis: The process evaluation after the pregnancy program was obtained from the frequency distribution table. Wilcoxon signed rank tests were performed to compare the usefulness of pregnancy programs and marital satisfaction during pregnancy and one and three months after childbirth. All analyses were performed using IBM SPSS Statistics 21.0. The significance level was set to equal or less than 0.05 .

- Qualitative analysis: Participants' free opinion on the program used a qualitative analysis method [15]. The free-form data was coded by considering the similarities and differences in the context and comparing them. After that, the level of abstraction of the code was raised, the category which expressed the meaning appropriately was generated, and the appropriateness of the category naming was examined. It was revised after being reviewed by a specialist in maternal nursing and midwifery.

\section{Ethical considerations}

Participation in the study was voluntary. All couples were provided written and verbal assurance that refusal or exclusion from the study would not affect their medical services. Consent was obtained from couples after they had read and understood the terms. In addition, participants were able to withdraw from the study at any point. This study was approved by the Clinical Research Ethical Review Board of Gunma PAZ University (approval number PAZ16-17).

\section{Results}

The researchers recruited 30 couples. Of these, 15 older primipara Japanese couples ( 15 wives and 15 husbands) who met the selection criteria participated in the program. All 15 couples responded to the questionnaires three times and their data was analyzed. The number of gestational weeks for pregnant women was $31.5(\mathrm{SD}=4.17)$ weeks (range 37-25) at the time of class participation.

\section{Participant attributes}

The participants' characteristics are summarized in Table 2. The wives' mean age was $36.7(\mathrm{SD}=1.6)$ years and husbands' mean age were $38.0(\mathrm{SD}=4.3)$ years. The average EPDS score of the wives was 5.4 points during pregnancy, 5.6 points one month after childbirth, and 3.9 points three months after childbirth. There was no significant difference between before and after participating in the program. This suggests that older primiparas were unlikely to be suffering from depression between the pregnancy period and one and three months after childbirth.

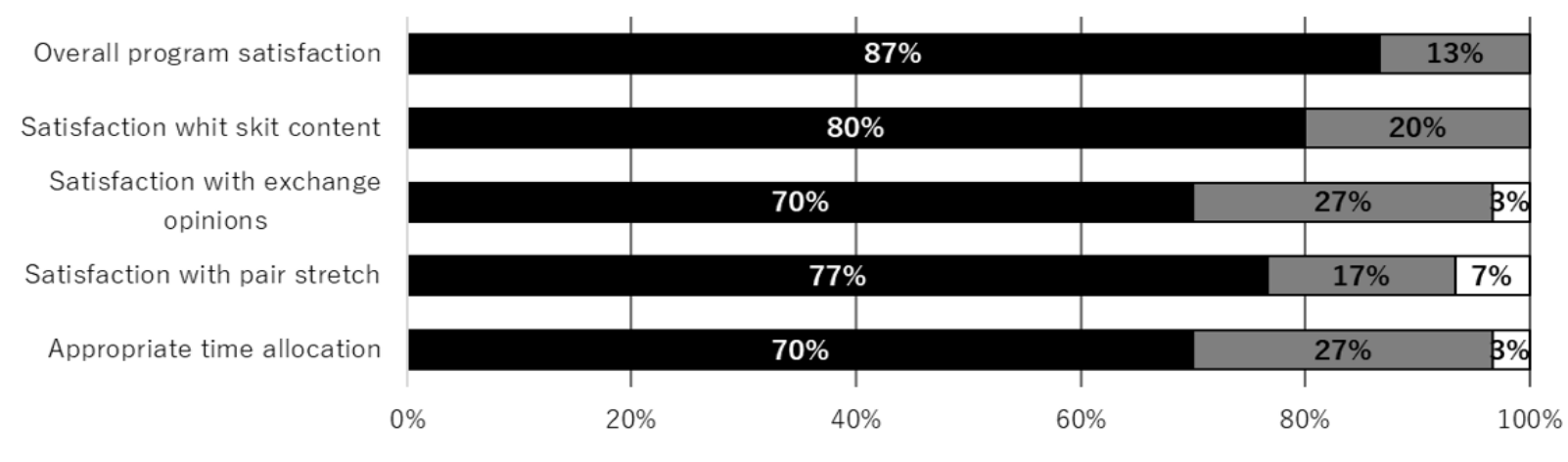

- Agree and somewhat agree $\square$ Neiter agree nor disagree $\square$ Disagree and somewhat disagree

Figure 1: Process evaluation after the pregnancy program. 


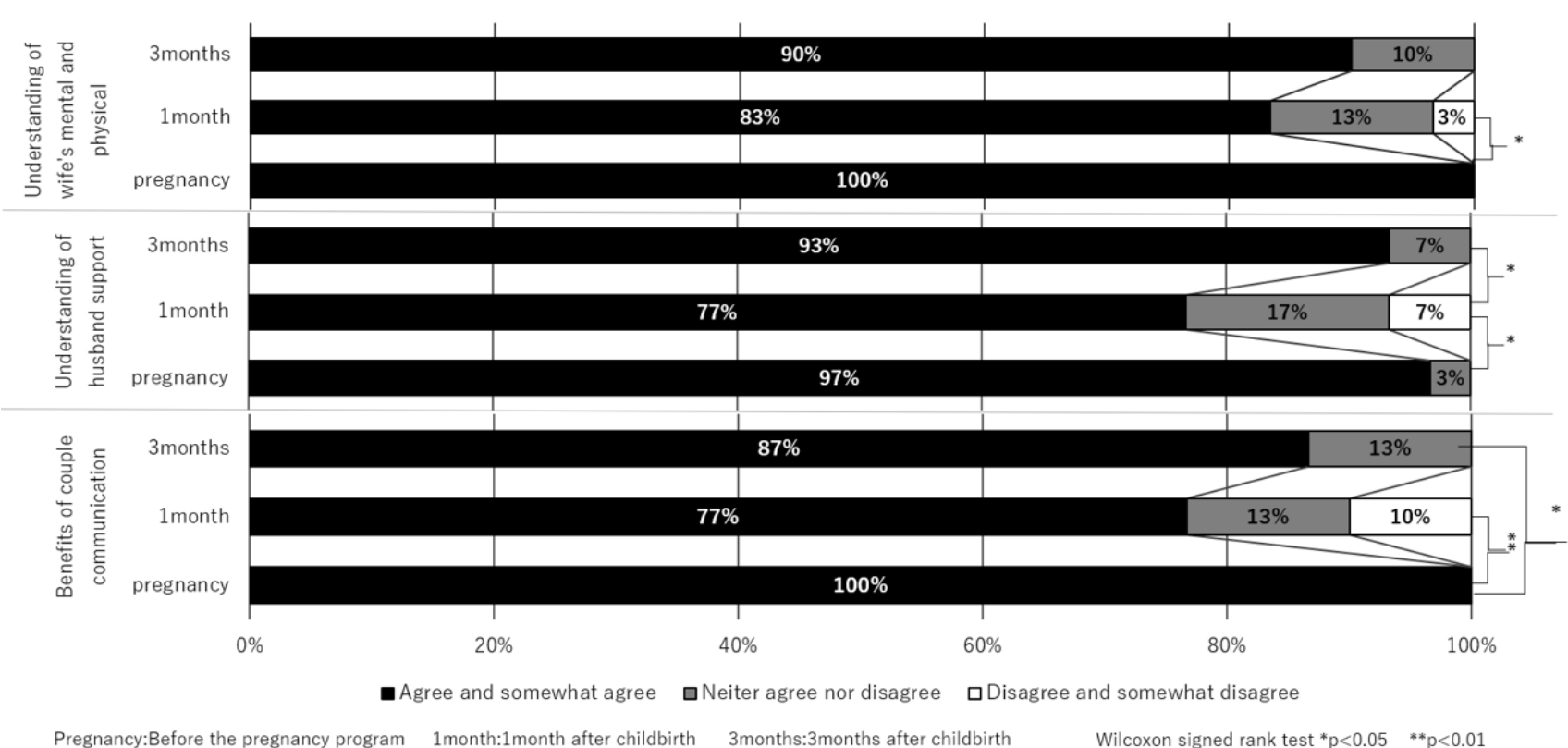

Figure 2: Evaluation of the usefulness of the pregnancy program at one and three months after childbirth.

Table 2: Characteristics of the participants.

\begin{tabular}{|c|c|c|c|c|c|}
\hline Age(years) & Mean & SD & Range & \multicolumn{2}{|c|}{$\mathrm{n}=15$ couples } \\
\hline Wife & 36.7 & 1.6 & $35-40$ & & \\
\hline Husband & 38 & 4.3 & $32-45$ & & \\
\hline Background & & & & $\mathbf{n}$ & $\%$ \\
\hline $\begin{array}{l}\text { Establishment of the } \\
\text { pregnancy } \\
\text { Natural pregnancy } \\
\text { Infertility after pregnancy } \\
\text { Pregnancy progress } \\
\text { Regular progress } \\
\text { Wives' employment } \\
\text { Work } \\
\text { Husework } \\
\text { Husbands' employment } \\
\text { Work } \\
\text { Family structure } \\
\text { Nuclear family } \\
\text { Extended family } \\
\text { Childcare situation } \\
\text { Family support/satogaeri }\end{array}$ & & & & $\begin{array}{c}6 \\
9 \\
15 \\
10 \\
5 \\
15 \\
12 \\
3 \\
15\end{array}$ & $\begin{array}{l}40.0 \\
60.0 \\
100.0 \\
66.7 \\
33.3 \\
100.0 \\
80.0 \\
20.0 \\
100\end{array}$ \\
\hline EPDS & Mean & SD & Range & cut off point (n) & \\
\hline Pregnancy & 5.4 & 3.6 & $13-0$ & 2 & \\
\hline $1 \mathrm{M}$ & 5.6 & 4.0 & $12-0$ & 4 & \\
\hline $3 M$ & 3.9 & 3.0 & $8-0$ & 0 & \\
\hline
\end{tabular}

Satogaeri: Returning to their parents' home, Pregnancy: Before the pregnancy. Program, 1M: One month after childbirth, $3 \mathrm{M}$ : Three months after childbirth, cut off point: 9 point or more.

\section{Process evaluation}

- Process evaluation after the pregnancy program: After completion of the pregnancy program, 95\% of the participating couples gave good answers regarding their satisfaction with skits, exchanging opinions with participants, and pair stretching (Figure 1).

- Evaluation of the usefulness of the pregnancy program at one and three months after childbirth: Of the participants, $95 \%$ or more of the couples answered positively about the understanding of the wife's physical and mental burden, the importance of husband's support, and the usefulness of the couple's communication during pregnancy. However, one and three months after childbirth, all 3 items decreased to about $80 \%$, indicating a significant difference $(\mathrm{p}<0.5)$ (Figure 2).

- Couples' opinions about the program: As a result of classifying the opinions of couples after the pregnancy program and one and three months after childbirth, positive opinions such as "In depth understanding of the physical and mental health of wife", "Development of intimacy of couples", and "Satisfaction with participating in a program with their partner" were extracted. However, "Difficulty in continuing the program" and "Requests and issues regarding program content" were also extracted (Tables 3(1) and $3(2)$ ).

\section{Outcome evaluation of QMI}

The average QMI of the wife and husband was $20.1(\mathrm{SD}=2.58)$ for the wife and $21.1(\mathrm{SD}=2.81)$ for the husband at the time of pregnancy. In comparison, before and after participating in the program, there was no significant difference between pregnancy and one and three months after childbirth (Table 4).

\section{Discussion}

\section{Contents of the marital relationship support program developed for older primiparas couples}

According to adult education theory, when programming in adult education, visual, auditory, and sensory methods are important to be adopted for each subject to ensure that the instructor's message is communicated to the adult students [11]. This program adopted three methods and consisted of lectures and exercises. In the lecture, the characteristics of the physical and mental health of the older primipara and the importance of husband's support were set from the needs of the couple, extracted by qualitative research 
Table 3(1): Opinions of couples after the pregnancy program ( $n=15$ couples).

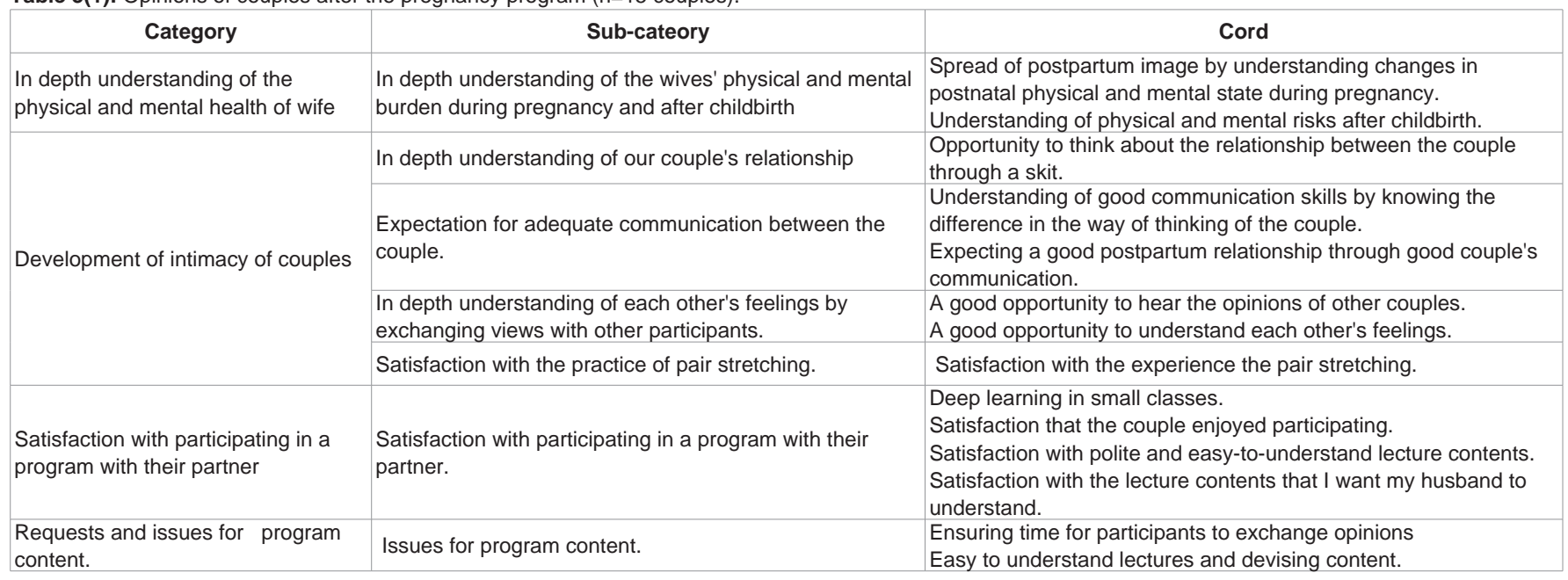

Table 3(2): Opinions of couples in one and three months after childbirth ( $n=15$ couples).

\begin{tabular}{|c|c|c|}
\hline Category & Sub-category & Cord \\
\hline $\begin{array}{l}\text { In depth understanding of the } \\
\text { physical and mental health } \\
\text { of wife }\end{array}$ & $\begin{array}{l}\text { Helped to understand the physical and } \\
\text { mental health of the wife after childbirth }\end{array}$ & $\begin{array}{l}\text { - } \quad \text { Objective view of one's mental state after childbirth. } \\
\text { - } \quad \text { Helped to understand each other's physical and after childbirth. } \\
\text { Useful for application to life centered on childcare after childbirth }\end{array}$ \\
\hline \multirow{3}{*}{$\begin{array}{l}\text { Development of intimacy of } \\
\text { couples }\end{array}$} & $\begin{array}{l}\text { Utilization and change of marital } \\
\text { cooperation }\end{array}$ & $\begin{array}{l}\text { Utilization for husband's support to wife by understanding the physical and } \\
\text { mental burden of wife. } \\
\text { - } \quad \text { Changes in husband and wife's cooperative relationship with postnatal role. }\end{array}$ \\
\hline & $\begin{array}{l}\text { Practice effective communication by } \\
\text { understanding the differences in feelings } \\
\text { of the couple }\end{array}$ & $\begin{array}{l}\text { Increased communication opportunities for couples Useful for communication } \\
\text { by understanding the difference in the way of thinking of the couple. } \\
\text { Useful for communication skills when requesting support from the other } \\
\text { party. } \\
\text { Reflecting on how to engage with one's own partner through marital } \\
\text { communication. }\end{array}$ \\
\hline & Practical use of pair stretching & $\begin{array}{ll}- & \text { Intimate pair stretching from husband } \\
\text { - } & \text { Awareness that massage can be a communication tool }\end{array}$ \\
\hline $\begin{array}{l}\text { Difficulty in continuing the } \\
\text { program }\end{array}$ & $\begin{array}{l}\text { Difficulty in continuing to utilize pregnancy } \\
\text { programs during busy postpartum days }\end{array}$ & $\begin{array}{l}\text { Difficult to secure stretching time due to busyness after delivery rather than } \\
\text { during pregnancy. } \\
\text { Lack of communication time between husband and wife due to busy } \\
\text { parenting after childbirth. } \\
\text { Prioritize work over husband's postnatal care by losing awareness of } \\
\text { pregnancy program. }\end{array}$ \\
\hline $\begin{array}{l}\text { Requests and issues } \\
\text { regarding program content }\end{array}$ & Requests regarding program content & $\begin{array}{l}\text { Hope for a specific postnatal housework and parenting program that her } \\
\text { husband understands Hope to be able to remember the contents of the } \\
\text { pregnancy program even after childbirth. } \\
\text { Hope for a postpartum program that the couple can join after the birth }\end{array}$ \\
\hline
\end{tabular}

Table 4: Quality Marriage Index (QMI) for pregnancy, one and three months after childbirth ( $n=15$ couples).

\begin{tabular}{|c|c|c|c|c|c|c|c|c|}
\hline \multirow{2}{*}{} & \multicolumn{2}{|c|}{ Pregnancy } & \multicolumn{2}{|c|}{ 1M } & \multicolumn{2}{c|}{ 3M } & \multirow{2}{*}{ z value } & \multirow{2}{*}{ p value } \\
\cline { 2 - 9 } & Mean & SD & Mean & SD & Mean & SD & & \\
\hline Wife & 20.1 & 2.58 & 21.0 & 3.14 & 21.2 & 3.01 & -1.375 & 0.169 \\
\hline Husband & 21.1 & 2.81 & 21.7 & 2.59 & 21.1 & 2.89 & -0.105 & 0.916 \\
\hline
\end{tabular}

Note: Wilcoxon signed rank test.

Pregnancy: Before the Pregnancy program. M: One month after childbirth. 3M: Three months after childbirth

on the development process of this program. The information was presented visually using slides and booklets. Participatory exercises deepened the understanding of couple's effective communication skills by allowing them to visualize postpartum childcare situations using skits. In the exercise, a peer empowerment effect was expected by sharing the thoughts of the wife and husband about the marital relationship between the participating couples. Furthermore, by incorporating pair stretches from a sensory point of view, the marital intimacy was promoted, and the wife's physical burden was reduced.
Therefore, the pregnancy program utilizing adult education theory was easy for the participating couples to understand and remember. Furthermore, it led to the purpose of the program to understand the physical and mental burdens of older primiparas and to strengthen their marital relationships.

\section{Assessing the marital relationship support program for older primiparas couples}

From the opinions of couples who participated in the program, "In-depth understanding of the physical and mental health of wife "and" Development of intimacy of couples" was extracted after the pregnancy program and one and three months after childbirth. The results of the participants' opinions revealed that the program helps to understand the physical and mental burdens of older primiparas and strengthen postnatal marital relationships. On the other hand, in "Requests/Issues for Program Content", opinions were extracted regarding wanting to increase the time for exchanging opinions between participating couples. In a study on a free and interactive childbirth preparation class [10], a couple was mentally prepared 
for childbirth because of the satisfaction of sharing the childbirth process together and the peace of mind of sharing the opinions of the participating couples. Similarly, the couples in this study had few opportunities to participate in the pregnancy program, so they were able to objectively view their husband and wife through exchanging opinions among the participants. In addition, the results of the outcome evaluation showed no significant difference in the QMI between the wife and husband before and after participating in the program. In other words, since the QMI of postpartum couples did not decrease, it is possible that the couples who participated in the pregnancy program could prevent a decrease in satisfaction with the postpartum marital relationship. Therefore, among the contents of this program, the segment of participatory exercises, that included exchange of opinions among participants, contributes to the development of intimacy between the couple during pregnancy as they are able to share their thoughts and feelings. This may lead to a good marital relationship after childbirth, further preventing postpartum crisis.

As a result of the process evaluation of the pregnancy program, about $95 \%$ of the participating couples highly evaluated the marital relationship support program for older primiparas couples in terms of understanding, utilization, and satisfaction of the program contents. However, the usefulness assessment of the pregnancy program dropped to about $80 \%$ at one and three months after childbirth. In addition, the couple's opinion regarding "difficulty in continuing the program" was extracted at one and three months after childbirth.

Therefore, this program was evaluated as a program with high information acquisition and satisfaction. However, there were issues regarding the usefulness of the program. It was suggested that a postnatal program should be held for couples to continue learning about the pregnancy program after childbirth.

\section{Limitations of research and future issues}

Future studies can focus on developing a couple relationship support program for couples not limited to older primiparas. In addition, to increase the usefulness of this program and strengthen marital relationship after childbirth, it is necessary to implement a continuous program from pregnancy to postpartum. In the future, it will be necessary to further refine the program based on the data obtained in this study, increase the number of subjects sufficiently, and verify the effect in a two-group randomized controlled trial.

\section{Conclusion}

In this study, adult learning theory was used to develop a program to understand the physical and mental health of older primiparas and to strengthen marital relationships. The couples who participated in the program highly evaluated the level of understanding and satisfaction of information and the free opinion of the program was evaluated as helping to improve mutual understanding and sharing of thoughts and feelings. Outcome evaluation showed no significant reduction in postpartum marital satisfaction after participation in the program. However, there was a significant reduction in the usefulness of the program at one and three months postpartum than after participating in the pregnancy program. Findings indicate that this program improves marital relationships with high information acquisition and satisfaction. However, there were issues regarding the usefulness of the program. It was suggested that a postnatal program should be held for the couple to continue learning about the pregnancy program after childbirth.

\section{Acknowledgement}

The authors would like to thank couples who took part in this study.

\section{Fundling Disclosure}

This research was funded by the Grant-in-Aid for Scientific Research in 2017 (Basic Research c), Japan.

\section{Contributions}

Study design: $\mathrm{KN}$; date analysis: $\mathrm{KN}$ and $\mathrm{AH}$; and manuscript preparation: $\mathrm{KN}$ and $\mathrm{TN}$.

\section{References}

1. Ministry of Health, Labor and Welfare of Japan. Japanese vital statistics 2019.

2. Sakajo A, Mori E, Maehara K, Maekawa T, Ogawa H, Morita A, et al. Older Japanese primiparas' experiences at the time of after post-delivery hospital stay. Int J Nurs Pract. 2014; 20: 9-19.

3. Satoh A, Kitamiya C, Kudoh H, Watanabe M, Menzawa K, Sasaki H. Factors associated with Late postpartum depression in Japan. Jpn J Nurs Sci. 2009; 6: 27-36.

4. Belsky J, Kelly J, Ajimine K [translation]. The transition to parenthood. First edn. Tokyo. Soushisha. 1995.

5. Uchida A, Tsuboi K. Postpartum depression, First edn. Tokyo: Poplar Shinsho. 2013.

6. Nakajima K, Hayakawa Y, Usui A. The mental and physical health of older primiparas and couples' awareness of wives' satisfaction with their husbands' support in the first and third months after childbirth. J Jpn Acad Midwif. 2021.

7. Nakajima K, Usui A, Hayakawa Y. Feelings of older Japanese primiparous couples and satisfaction of older primiparous wives with their husbands' support during pregnancy: Focus on the perceptions of pregnant couples. Nursing Open. 2020.

8. Suto M, Takahara K, Yamane Y, Ota E. Effects of prenatal childbirth education for partners of pregnant women on paternal postnatal mental health and couple relationship: A systematic review. J Affect Disord. 2017; 210: 115-121.

9. Yamaguchi S, Sato $\mathrm{Y}$. The effects of an educational program to promote firsttime fathers' participation in childcare and household chore. Int J Nurs Clin Pract. 2016; 3: 166: 1-6.

10. Nagamori K, Horiuchi S, Ito K. Experiences of expectant first-time fathers attending small group participative childbirth education class. J Jpn Acad Midwif. 2005; 19: 2: 28-38.

11. Knowles M. The Modern Practice of Adult Education: From Pedagogy to Andragogy. Revised ed. Cambridge Book Co. Cambridge. 1988.

12. Mori E, Iwata H, Sakajo A, Maehara K, Ogawa $H$, Maekawa $T$, et al. Postpartum experience of older Japanese primiparas during the first month after childbirth. Int J Nurs Pract. 2014; 20: 20-31.

13. Norton R. Measuring marital quality. A critical look at the dependent variable. J Marriage Family. 1983; 45: 141-151.

14. Moroi K. Perceptions of equity in the division of household labor. Jpn J Fami Psycho. 1996; 10: 15-30.

15. Sandelowski M. Focus of Research Methods Whatever happened to qualitative descriptions? Research in Nursing \& Health. 2000; 23: 334-340. 